\title{
DESENVOLVIMENTO AFETIVO - O PROCESSO DE APRENDIZAGEM E O ATRASO ESCOLAR*.
}

\author{
Adriana Vilela Jacob** \\ Sonia Regina Loureiro***
}

\section{RESUMO}

$O$ presente artigo apresenta algumas considerações sobre o atraso escolar, abordando a multiplicidade de fatores internos e externos envolvidos neste, destacando a aprendizagem como um indicador do processo de desenvolvimento e funcionamento afetivo das crianças. $O$ atraso escolar caracteriza-se como uma das principais queixas dos pais que procuram os serviços de psicologia para o atendimento de crianças.

\section{O ATRASO ESCOLAR E A PROCURA POR ATENDIMENTO EM SERVIÇOS DE SAÚDE.}

O atraso escolar constitui-se em uma das condições decorrentes da situação de fracasso escolar das crianças no sistema formal de ensino.

No Brasil sabe-se que a questão do ensino é muito séria. Boruchovitch (1994) comentando os dados do MEC de 1980, quanto às porcentagens de reprovações escolares e o elevado número de estudantes com atraso escolar, considerou o atraso como um dos importantes fatores relacionados ao abandono escolar de muitos estudantes.

Muitas vezes as dificuldades das crianças no processo educacional formal resultam numa elevada procura por serviços especializados de psicologia, cuja queixa principal é genericamente chamada de "problema de aprendizagem" (Marturano, 1993).

Em nosso meio, nos serviços de atendimento em psicologia infantil, o que pode ser observado é um grande número de encaminhamentos de crianças que já em início de escolarização trazem como queixa os problemas de aprendizagem. Esta queixa constitui-se no motivo principal de procura aos centros especializados em saúde infantil, caracterizando a maior proporção de demanda nas Unidades Básicas de Saúde, nos Ambulatórios Especializados e nas Clínicas

\footnotetext{
* Apoio FAPESP.

** Mestre em Saúde Mental e Doutoranda pela FMRP-USP.

*** Profa. Dra. do Departamento de Neurologia, Psiquiatria e Psicologia Médica da FMRPUSP.
}

Paidéia, FFCLRP-USP, Rib. Preto, Fev/Ago 96. 
Escolas de diversas localidades do Brasil (Lopez, 1984; Abramovay, Minosso \& Duarte, 1987; Silva, Munõz \& Cursino, 1987; Sales, 1989).

Vários estudos de caracterização do perfil da clientela infantil nos serviços de atendimento psicológico têm apontado o atraso escolar como um dos principais motivos de procura por ajuda psicológica (Martins \& Graminha, 1990; Santos, 1990; Figueiró \& Marturano, 1991; Marturano, Magna \& Murtha, 1992; Linhares, Parreira, Marturano \& Sant'anna, 1993).

De um modo geral, estes estudos mostraram uma clientela formada por crianças na faixa etária de sete a doze anos, com maior número de meninos, alunos das primeiras séries do primeiro grau, cuja queixa principal relacionouse às dificuldades escolares e ao desempenho acadêmico. Contudo, através da análise dos dados fornecidos pelos pais em entrevista diagnóstica, os autores têm chamado atenção para a associação de problemas emocionais e comportamentais à queixa principal.

As características mencionadas nestes estudos nacionais foram concordantes com as relatadas em estudos internacionais como os estudos de Rutter (1974) e Schachter, Pless \& Bruck (1991) que apontaram para maior incidência de problemas de aprendizagem em meninos, nas primeiras séries de escolarização e ainda a associação das queixas escolares a aspectos cognitivos, afetivos e/ou comportamentais.

Embora a aprendizagem escolar constitua-se em um dos indicadores da capacidade ampla de aprendizagem do indivíduo, na fase escolar o desempenho acadêmico é percebido pelos adultos como o principal parâmetro de identificação das possibilidades das crianças. Como colocaram Carvalho \& Térzis (1989), as dificuldades de aprendizagem escolar e o consequente atraso possivelmente são um dos únicos padrões de referência que as famílias têm para avaliar seus filhos, embora determinados problemas psicológicos, coincidentes com a fase de escolarização, não se caracterizem necessariamente como um problema de aprendizagem.

\section{ATRASO ESCOLAR E A MULTIPLICIDADE DE FATORES ENVOLVIDOS NA SUA PRODUÇÃO.}

Múltiplos fatores ambientais e individuais estão envolvidos na questão da aprendizagem e do atraso escolar. Fernandez (1990) propõe dois grupos de fatores vinculados às dificuldades de aprendizagem, sendo o primeiro relacionado à estrutura educacional e o segundo correspondendo a causas internas individuais do sujeito ou de seus familiares.

O processo de aprendizagem é influenciado por uma multiplicidade de 
determinantes culturais, sociais e políticos que caracterizam os fatores ambientais mais amplos, dentre os quais se coloca a estrutura educacional. A qualidade do ensino nas escolas, o papel social da escola na vida dos indivíduos (Lindalh, 1988) e o preparo dos professores (Focesi, 1990a; Focesi, 1990b; Oliveira \& Silva, 1990) entre outros têm um importante papel na condição de aprendizagem proporcionada às crianças.

Segundo Lindahl (1988), em nossa sociedade a escola mantém-se como o principal veículo de educação sistemática, restringindo-se a transmitir às crianças de modo geral apenas os valores, conhecimentos e comportamentos da cultura dominante, nem sempre considerando o que a criança traz consigo de aprendizagens anteriores à escolarização. Com isto a desadaptação da criança aos padrões esperados pela escola pode decorrer da descontinuidade das vivências sociais e das diferentes expectativas de cada classe social.

Considerando os fatores ambientais, o processo de aprendizagem é ainda influenciado por determinantes mais imediatos que dizem respeito às características do grupo familiar do indivíduo quanto ao nível sócio-econômico, o letramento, e a valorização do ensino formal (Lindahl,1988). A exposição ao stress psicossocial múltiplo como uma condição presente na história de vida da criança, pode caracterizar-se como agente que fragiliza o indivíduo, favorecendo as dificuldades frente às demandas escolares (Marturano, Magna \& Murtha, 1992; Marturano, Linhares \& Parreira, 1993).

Os fatores individuais, internos da criança, mais comumente identificados segundo Pain (1985) são relativos a aspectos biológicos, cognitivos e/ou afetivos, que isoladamente ou em interação determinam as condições do aprendizado.

Algumas alterações orgânicas e neurológicas podem afetar a capacidade cognitiva e adaptativa. $O$ rebaixamento cognitivo, secundário ou não a outra patologia, definido como retardo mental implica em significativa inferioridade do funcionamento intelectual global.

O Manual de diagnóstico e estatística dos distúrbios mentais, DSM-III$R$ (APA, 1989) definiu retardamento mental na criança a partir da primeira infância sugerindo os seguintes critérios:

a) "significativa inferioridade do funcionamento intelectual global - um QI de 70 ou inferior em teste de QI administrado individualmente";

b) comprometimento no funcionamento adaptativo ou concomitância de déficits, observados através da eficiência do indivíduo em "alcançar os padrões esperados para a sua idade, para seu grupo cultural, em áreas como: habilidades sociais e responsabilidades, comunicação, habilidades de vida diária, independência pessoal e auto-suficiência" (p.35).

Considera-se que os diferentes níveis de funcionamento cognitivo

Paidéia, FFCLRP-USP, Rib. Preto, Fev/Ago 96. 
acarretem desempenhos variados, comparativamente aos padrões esperados para cada faixa etária, dentro de um mesmo grupo sócio-cultural. A deficiência mental enquanto comprometimento do funcionamento intelectual global prejudica o funcionamento adaptativo do indivíduo, resultando frequentemente em atraso escolar (Kaplan \& Sadock, 1986; APA, 1989).

Nas diversas estruturas educacionais, dos mais variados países do mundo, observou-se que em cada grupo etário de crianças em idade escolar algumas não obtém desempenho adequado em relação ao seu nível geral de funcionamento intelectual, considerando-se aspectos específicos de realizações em uma ampla gama de atividades e aprendizagens escolares (CID-10, 1993).

Contudo, muitas crianças sem alterações orgânicas ou cognitivas apresentam dificuldades de aprendizagem, o que configura como hipótese explicativa, a interferência do funcionamento afetivo e das funções adaptativas na aprendizagem.

\section{A APRENDIZAGEM ENQUANTO FUNÇÃO INTEGRADORA DO EGO.}

A aprendizagem enquanto função egóica caracteriza-se por um processo amplo, diretamente relacionado ao desenvolvimento psicológico, permeando todas as fases da vida e sofrendo múltiplas influências.

A aprendizagem escolar, sob este ponto de vista, constitui-se em um dos indicadores da capacidade de aprendizagem do indivíduo, caracterizando a forma como a criança percebe e lida com o seu meio, o que se relaciona ao seu padrão de adaptação e de saúde mental.

O processo do desenvolvimento psicológico do ser humano tem sido objeto de estudo de muitas abordagens teóricas. As abordagens psicodinâmicas consideram que no processo de desenvolvimento psicológico, a criança vivencia conflitos próprios em cada etapa do crescimento, com necessidades internas que se confrontam com a realidade externa. A experiência interna decorrente das várias vivências permite a formação da auto imagem, do ego e consequentemente dos mecanismos de defesa do ego. Segundo Klein (1974) desde o nascimento do bebê a personalidade vai se construindo e as experiências internas decorrentes do interjogo entre a realidade subjetiva e a realidade objetiva vão configurando o mundo interno.

Erikson (1971) propõe uma compreensão da aprendizagem como produto da interação das necessidades que ao longo do desenvolvimento vão se modificando e configurando novos conflitos. A maneira como estes conflitos resolvem-se passa a ter um papel importante na formação da personalidade do 
indivíduo, influenciando as etapas posteriores do desenvolvimento e a forma destas serem experienciadas.

Nesta concepção, ao nascer a criança não se reconhece enquanto indivíduo, e percebe o mundo como parte integrante de si, não distinguindo seu mundo interno do meio externo.

Erikson relacionou estágios e faixas etárias com as etapas vivenciadas neste processo, referindo como tarefas de resolução de conflitos do ego, a relação entre as necessidades internas e as respostas do ambiente. De acordo com sua concepção, quando o desenvolvimento acontece de uma forma adequada, cada etapa bem resolvida favorecerá a continuidade do bom desenvolvimento, e por outro lado, o fracasso em uma dada etapa poderá comprometer a seguinte.

Segundo Erikson (1971) nos primeiros 18 meses de vida, a vivência do bebê de necessidades físicas tais como fome e frio, as sensações de dores, e as necessidades psicológicas de calor humano e afeto despertam na criança a expectativa e urgência de satisfação. A percepção da criança de que precisa de um outro indivíduo separado de si para poder receber os cuidados de que necessita tem então um papel central nos primeiros rudimentos de ego.

Por volta dos 18 meses a 3 anos, quando percebe o externo com confiança e vivencia a satisfação das suas necessidades de uma forma adequada, a criança começa a se perceber como indivíduo e passa a experimentar seus limites e possibilidades, buscando autonomia e controle sobre si. À medida em que a criança sente-se encorajada nesse processo, com uma imagem de si predominantemente positiva, experimenta independência e a possibilidade de lidar com novos desafios.

Aos poucos, na faixa etária de 4 a 5 anos, a criança passa a necessitar planejar e realizar tarefas, introjetando papéis sociais e a necessidade de ser aceita enquanto alguém produtivo. $O$ conflito central nesta etapa decorre da necessidade da livre iniciativa contrapondo-se às regras sociais. Novamente, a experiência interna de auto imagem positiva favorecerá a possibilidade da criança exprimir-se e colocar-se frente às regras.

Dentro dessa abordagem, independentemente da cultura, num desenvolvimento tido como normal, as crianças na faixa etária dos 6 aos 12 anos experimentam a necessidade de aprender com os adultos e desejam mostrarse competentes e com capacidade produtiva. Esta faixa etária em nosso meio corresponde aos anos iniciais de escolarização, cujo principal objetivo é que as crianças sejam alfabetizadas.

Lindahl (1988) afirmou que a alfabetização e o desempenho escolar em nossa cultura são relacionadas à definição das possibilidades de sucesso ou, em oposição, de marginalização dos indivíduos, tendo em função disso um papel 
tão importante na vida das crianças e das suas famílias. Considerou que, na cultura brasileira, a escola é a principal instituição responsável pela transmissão dos conhecimentos e valores que são requisitos para que os indivíduos tenham acesso ao preparo específico necessário para a produção e o trabalho.

Neste contexto, a escola pode ser entendida como o representante formal desta etapa de aprendizagem em nossa cultura (Lindahl,1988), constituindo-se em um importante agente socializador, ampliando as possibilidades de aquisição de conhecimento e de experiências afetivas.

O não cumprimento da tarefa psicossocial atribuída às crianças nesta etapa, cujos papéis sociais e exigências formais de responsabilidade caracterizamse pela produtividade escolar, está associado ao fracasso escolar, e ao comprometimento da aceitação e popularidade da criança pelos colegas e adultos, favorecendo baixa auto estima, podendo relacionar-se em alguns casos às condutas anti-sociais e delinqüentes (Linhares et al., 1993).

A capacidade adaptativa da criança evidencia-se nas formas como ela lida com as exigências próprias desta fase, tornando os níveis de aquisições e amadurecimento alcançados até este momento mais evidentes. Assim, a aprendizagem formal relacionada às atividades acadêmicas, constitui-se em uma das dimensões do processo de amadurecimento, refletindo as aquisições das etapas anteriores do desenvolvimento e os recursos e limites da criança do ponto de vista da saúde mental.

O resultante destas vivências, segundo Pain (1985) engloba uma multiplicidade de fatores e condições internas e externas que se relacionam à forma da criança vivenciar situações de aprendizagem. Segundo Ocampo \& Arzeno (1981), a aprendizagem enquanto função egóica denota as possibilidades adaptativas do indivíduo ao longo da vida e as suas condições para lidar com dados de realidade, expressando sua estrutura de personalidade, favorecendo assim o levantamento de hipóteses sobre sua saúde mental atual e as possibilidades de seu desenvolvimento futuro.

\section{FATORES AFETIVOS ASSOCIADOS AO ATRASO ESCOLAR.}

Vários autores na tentativa de compreensão dos problemas de aprendizagem têm focalizado em seus estudos os fatores afetivos associados.

Luzuriaga (1972), analisando a questão da aprendizagem e sua relação com fatores afetivos, discutiu que o fracasso escolar pode decorrer da inadequação do uso do potencial intelectual, estando este a serviço de dificuldades emocionais. Assim, a criança utilizaria seus recursos intelectuais em um funcionamento defensivo, numa atividade constante da mente de evitar o conhecimento. $\mathrm{O}$ 
investimento contra a própria inteligência estaria associado à negação dos vínculos significativos, num processo auto destrutivo de desconexão mental.

Os mecanismos inconscientes relacionados às dificuldades de aprendizagem também foram abordados por Pain (1985) ao descrever os fatores afetivos como um dos fatores relacionados aos problemas de aprendizagem. Em seu trabalho, tratou o não aprender como inibição ou sintoma, caracterizando essa reação como uma interdição da satisfação através do afastamento da realidade e busca de satisfação à nível da fantasia, favorecendo a fixação e impedindo o desenvolvimento. A autora considerou como manifestação deste processo uma atividade cognitiva empobrecida, mecanizada e passiva, caracterizando um bloqueio ao desenvolvimento com comprometimento dos reais potenciais.

Fernandez (1990) também considerou que o fracasso escolar relacionase basicamente a processos e desejos inconscientes restritivos do potencial intelectual decorrentes de dificuldades a nível afetivo.

Em outro trabalho, Fernandez (1992) discutiu a relação entre os impulsos agressivos e o processo de aprendizagem, apontando para a necessidade da ação dos impulsos agressivos para a transformação e incorporação dos conhecimentos, num constante construir e reconstruir que se faz a dois (aprendiz e mestre). Neste sentido, as condutas agressivas caracterizariam-se por desvios na utilização dos impulsos agressivos que podem estar a serviço da destruição do pensamento e da criatividade, acarretando problemas de aprendizagem.

Em estudo de aplicação, Feshbach \& Feshbach (1987) observaram que o desenvolvimento cognitivo e a performance escolar sofreram interferência direta das disposições afetivas. A expressão de disposição afetiva depressiva e a agressividade, segundo os autores parecem fomentar e sustentar um funcionamento cognitivo empobrecido, com prejuízo nas realizações acadêmicas, o que foi observado principalmente nas crianças do sexo masculino.

Utilizando-se do "Children's Depression Inventary" no sentido de relacionar a depressão infantil com a dificuldade escolar, MacGee \& Willians (1988) observaram que as dificuldades escolares podem estar associadas a desordens emocionais, tipo depressivas, num espectro mais amplo.

Hall \& Haws (1989) ao estudar crianças com dificuldades escolares também observaram muitos indícios de associação dessas à sintomatologia depressiva.

Estes estudos mostraram a relação dos aspectos depressivos com as dificuldades escolares de crianças nos anos iniciais de escolarização.

Ao estudar as queixas que motivaram a procura por atendimento psicológico em uma Clínica Psicológica Infantil da Prefeitura de São Paulo,

Paidéia, FFCLRP-USP, Rib. Preto, Fev/Ago 96. 
Santos (1990) observou que $61,5 \%$ ocorriam em função de distúrbios de aprendizagem. $\mathrm{O}$ referido autor pode observar que na maioria das vezes as queixas escolares encobriam problemas a nível afetivo. As principais queixas a afetivo foram de nervosismo, impulsividade, oposição, choro fácil, baixa tolerância à frustração, falta de iniciativa, apatia, isolamento social, dependência, imaturidade, medos e manifestações somáticas difusas. Analisando estas queixas observa-se que elas podem ser divididas em dois grupos de sintomas, ou seja, queixas relacionadas à dificuldade de controle frente à frustração e queixas relacionadas à uma auto estima comprometida, com aspectos de depressão e ansiedade.

Nunes (1990) ao estudar 60 alunos de $2^{2}$ e $3^{2}$ série do $1^{\circ} \mathrm{grau}$, na faixa etária entre 8 e 12 anos observou uma relação significativa entre o fracasso escolar e o desamparo adquirido. As crianças, segundo a autora, passaram a desenvolver frente ao fracasso uma percepção de incapacidade frente aos eventos negativos que lhe diziam respeito, com tendência a apresentar traços de impotência e fragilidade que acabavam por comprometer seu desempenho escolar. Contudo o grupo se dividiu quando a autora buscou relacionar o desamparo adquirido à depressão. Em 50\% destas crianças os aspectos depressivos associados ao desamparo foram auto imagem negativa, apatia, baixo tônus vital e passividade. A outra metade do grupo, apesar dos sentimentos de impotência conservaram uma auto imagem favorável, possivelmente em função da elaboração das perdas e fracassos, e de questões ambientais mais amplas.

Os distúrbios de comportamento enquanto problemática afetiva também parecem relacionar-se às dificuldades de aprendizagem. Schachter, et al. (1991) observaram uma prevalência de $43 \%$ desse tipo de distúrbio em crianças que traziam como queixa o baixo rendimento escolar.

Ao estudar as crianças atendidas no Ambulatório de Psicopedagogia do HCFMRP-USP, Murtha, Magna \& Marturano, (1990) observaram que as crianças chegavam emocionalmente fragilizadas com sentimentos de inferioridade, e apresentavam melhora após inclusão num programa de suporte e dessensibilização a curto prazo, possivelmente pela representação interna de atendimento das suas necessidades, antes mesmo que se trabalhasse diretamente estas questões.

Marturano, Magna \& Murtha (1993) identificaram nas crianças que buscavam atendimento no Ambulatório de Psicopedagogia do HCFMRP-USP uma diversidade de padrões de reação indicativos de problemas afetivos e comportamentais. Nas crianças com um maior número de queixas predominaram manifestações ostensivas de agressão/ataque, com oposição, choro, irritação e agitação. Já entre as crianças com um menor número de queixas, observaram o 
predomínio de reações de evitação, afastamento, dependência e esquiva social, bem como sinais de pouco vigor nas ações, como apatia e lentidão. Estas observações foram semelhantes às de Santos (1990) em outro estudo nacional já referido.

Em um outro estudo, Linhares et al. (1993) observạram que as crianças que procuraram o serviço acima referido apresentavam como padrão de desadaptação afetivo-social "manifestações de nervosismo do tipo irritação; falta de motivação ou desinteresse; oposição ou resistência; agitação/choro ou grito; retraimento ou inibição social e/ou agressividade"(p.157), estes indicadores foram relacionados a impulsividade e baixa tolerância à frustração, caracterizando imaturidade afetiva.

Analisando-se os trabalhos citados, observou-se que no processo de aprendizagem escolar, a capacidade de adaptar-se e responder às demandas do meio pode favorecer ou dificultar as aquisiçōes, implicando em custo emocional que repercute sobre o desenvolvimento.

\section{COMENTÁRIOS FINAIS}

A questão do atraso escolar envolve uma complexidade de fatores de natureza diversa mas interrelacionados. Neste sentido, pode-se dizer que o atraso escolar caracteriza-se como um indicador de dificuldades no processo do desenvolvimento.

$\mathrm{Na}$ escolarização formal, as crianças enfrentam normalmente novas dificuldades, que podem ou não repercutir sobre o desempenho acadêmico. A forma como cada criança lida com estas dificuldades relaciona-se à qualidade dos seus recursos internos, que vem se estruturando ao longo dos anos, mais explicitada na situação coletiva de escolarização.

Assim, não se pode tomar o atraso escolar em si, como um fato isolado. Do ponto de vista da interferência de fatores relacionados ao próprio sujeito, no seu processo de desenvolvimento afetivo o atraso escolar pode estar representando dificuldades internas da criança no lidar com a realidade muitas vezes adversa, e neste aspecto ser considerado como um sintoma de dificuldades afetivas. $O$ atraso escolar parece ter também uma repercussão interna importante, afetando processos intra-psiquicos ligados à formação da identidade, e neste aspecto ser considerado como uma variável favorecedora de dificuldades afetivas.

Em ambos os aspectos, o atraso escolar tido como sintoma ou como favorecedor da dificuldade afetiva, observa-se que as crianças que vivenciam a experiência de atraso escolar experimentam um elevado custo afetivo relacionado ao processo do aprender, com possíveis repercussões sobre o desenvolvimento 
da estrutura da personalidade.

A atenção psicológica à criança com atraso escolar mostra-se necessária tendo-se em conta o sofrimento psíquico relacionado aos custos afetivos do aprender e a etapa do desenvolvimento afetivo em questão.

\section{REFERÊNCIAS BIBLIOGRÁFICAS}

ABRAMOVAY, M.L.; MINOSSO, M.A. \& DUARTE, W.F. (1987) Características da clientela da clínica-escola de psicologia da Faculdade de Santo Amaro - OSEC. Programas e Resumos da XVII Reunião Anual de Psicologia da Sociedade de Psicologia de Ribeirão Preto, p.279, Ribeirão Preto:SBP.

AMERICAN PSYCHIATRIC ASSOCIATION (APA) (1989) - Manual de Diagnóstico e Estatística dos Distúrbios Mentais DSM-III-R. $3^{2}$ Edição Revisada, Tradução de Lúcia Helena Siqueira Barbosa, São Paulo, Ed. Manole.

BORUCHOVITCH, E. (1994) - As variáveis psicológicas e o processo de aprendizagem: uma contribuição para a psicologia escolar. Psicologia: Teoria e Pesquisa, 10(1),129-39.

CARVALHO, R.M.L.P. \& TÉRZIS, A. (1989) - Caracterização da clientela atendida na Clínica de Psicologia do Instituto de Psicologia da PUCCAMP. Estudos Psicológicos, 1: 94-109.

CID-10 (1993) - Classificação de Transtornos Mentais e de Comportamento: Descrições clínicas e diretrizes diagnósticas - Coord. Organização Mundial da Saúde; trad. Dorgival Caetano - Porto Alegre: Artes Médicas. ERIKSON, E.H. (1971) - Infância e Sociedade. Rio de Janeiro, Zahar.

FERNANDEZ, A. (1990) - A inteligência aprisionada. Porto Alegre, Artes Médicas.

FERNANDEZ, A. (1992)- Agressividade. Qual o teu papel na aprendizagem?

- Trabalho apresentado na II Jornada de Estudos Pedagógicos em Porto Alegre. Apostila mimeografada trad. Elaine Tavares. Porto Alegre.

FESHBACH, N.D. \& FESHBACH, S. (1987) - Affective Processes and Academic Achievement. Child Development, 58: 1335-47.

FIGUEIRO, M.B. \& MARTURANO, E.M. (1991) - Análise da demanda infantil no serviço de psicologia de um centro de saúde. In: Reunião Anual de Psicologia, 21, Comunicações científicas em psicologia, Ribeirão Preto, 1: 235 .

FOCESI, E. (1990a) - Educação em saúde: Campos de atuação na área escolar.

Revista Brasileira de Saúde escolar 1(1),19-21. 
FOCESI, E. (1990b)- Educação em saúde na escola. O papel do professor. Revista Brasileira de Saúde escolar, 1(2):5-9.

HALL, C.W. \& HAWS, D. (1989) - Depressive Symptomatology in learningdisabled and nonlearning-disabled students. Psychology in the Schools, 26: 359-364.

KAPLAN, H. \& SADOCK, B.J. (1986) - Compêndio de Psiquiatria Dinâmica, $3^{\text {a }}$ ed., p.750-95, Artes Médicas, Porto Alegre.

KLEIN, M. (1974) - Inveja e Gratidão. Rio de Janeiro, Imago.

LINDAHL, N.Z. (1988) - Personalidade humana e cultura: aplicações educacionais da Teoria de Erik Erikson. Revista brasileira de estudos pedagógicos, Brasília, 69(163):492-509.

LINHARES, M.B.M., PARREIRA, V.L.C., MATURANO, A.C. \& SANT'ANNA, S.C. (1993) - Caracterização dos motivos da procura de atendimento infantil em um serviço de psicopedagogia clínica.Medicina, Ribeirão Preto, 26(2): 148-60.

LOPEZ, A.M. (1984) - Características da Clientela de Clínicas. In: Macedo, R.M.(org.). Psicologia e Instituição. São Paulo, Cortez.

LUZURIAGA, I. (1972) - La inteligência contra si mesma. Buenos Aires, Editorial Psique.

MAcGEE, R. \& WILLIANS, S. (1988) - Childhood Depression and Reading Ability: Is there a Relationship? The Journal of school Psycology. 26: 391-393.

MARTINS, M. A. \& GRAMINHA, S. S. V. G. (1990) - Caracterização da população que procura o serviço de atendimento psicológico infantil ligado à Universidade. Resumos da XX Reunião Anual de Psicologia da Sociedade de Psicologia de Ribeirão Preto. p.190, Ribeirão Preto:SBP. MARTURANO, E.M. (1993) - Os problemas de aprendizagem na visão do profissional de saúde. In: Temas em Educação Especial 2. São Carlos, UFSCar, p.221-234.

MARTURANO, E.M; LINHARES, M.B. \& PARREIRA, V.L.C. (1993) Problemas emocionais e comportamentais associados a dificuldades na aprendizagem escolar. Medicina, Ribeirão Preto, 26(2): 161-175.

MARTURANO, E.M., MAGNA, J.M. \& MURTHA, P.C. (1992) - Contribuição ao diagnóstico das dificuldades de aprendizagem escolar. Revista Psicopedagogia, 11: 7-15.

MARTURANO, E.M., MAGNA, J.M. \& MURTHA, P.C. (1993) - Procura de atendimento psicológico para crianças com dificuldades escolares: Um perfil da clientela. Psicologia: Teoria e Pesquisa, 9(1): 207-26.

MURTHA, P.C.; MAGNA, J.M. \& MARTURANO, E.M. (1990) -

Paidéia, FFCLRP-USP, Rib. Preto, Fev/Ago 96. 
Determinação dos efeitos de uma modalidade de atendimento psicopedagógico. Resumos da XX Reunião anual de Psicologia da Sociedade de Psicologia de Ribeirão Preto, p.161, Ribeirão Preto: SBP. NUNES, A.N.A. (1990) - Fracasso escolar e desamparo adquirido. Psicologia:

Teoria e Pesquisa, Brasília, 6: 139-154.

OCAMPO, M.L.S. \& ARZENO, M.E.G. (1981) - O processo psicodiagnóstico e as técnicas projetivas. São Paulo: Martins Fontes.

OLIVEIRA, M.L.C.L. \& SILVA, M.T.A. (1990) - Educação em saúde: repensando a formação de professores. Revista Brasileira de Saúde escolar, 1(2): 13-19.

PAIN, S. (1985) - Diagnóstico e Tratamento dos Problemas de Aprendizagem. Porto Alegre: Artes Médicas.

RUTTER, M. (1974) - Emotional disorder and educational underachievement. Archives of Disease in Childhood, 49: 249-256.

SALES, J.R. (1989) - Estudo sobre a clientela da área de saúde mental em Varginha. Psicologia - Ciência e Profissão, 9(2): 22-26.

SANTOS, M.A. (1990) - Caracterização da clientela de uma clínica psicológica da Prefeitura de São Paulo. Arquivos brasileiros de Psicologia, 42(2): 79-94.

SCHACHTER, D.C.; PLESS, B. \& BRUCK, M. (1991) - The prevalence and correlates of behavior problems in learning. Canadian Journal of Psychiatry, 36: 232-31.

SILVA, R.C., MUÑOZ, M.J. \& CURSINO, E. A (1987) - Atuação psicológica na atenção primária à saúde (APS): análise da demanda clínica II. Resumos da XVII Reunião Anual de Psicologia da Sociedade de Psicologia de Ribeirão Preto, p.296, Ribeirão Preto, SBP.

\section{ABSTRACT}

In this article we present some considerations about being left behind in school, with an analysis of the multiple internal and external factors involved in this, and with emphasis on learning as an indicator of the process of affective development and functioning of children. Being left behind in school is one of the major complaints of parents who look for psychology services for their children.

Key words: Child development, Affective development, Learning, Learning disabilities.

Palavras-chave: Desenvolvimento Infantil, Desenvolvimento Afetivo, Aprendizagem, Atraso escolar. 